\title{
Calculation of expected remaining lifetime of dialysis patients in Japan
}

Shigeru Nakai ${ }^{*}$ (D, Atsushi Wada ${ }^{2}$, Kenji Wakai ${ }^{3}$, Masanori Abe $^{4}$ and Kosaku Nitta ${ }^{5}$

\begin{abstract}
Background: The expected remaining lifetime of dialysis patients in Japan was only reported in 2003 and has not been reported thereafter. From 2003 to the present, several new therapeutic agents have been introduced. These events may have improved outcomes for dialysis patients. Thus, expected remaining lifetime of dialysis patients in Japan was newly calculated in 2015.

Methods: The Japanese Society for Dialysis Therapy Renal Data Registry database was used for analyses. From this database, the following three indexes were compiled: the number of surviving dialysis patients (198,125 males and 111,962 females) at the end of 2014 and the number of surviving (179,649 males and 101,758 females) and dead (18,044 males and 111,417 females) patients at the end of 2015. Based on these values, expected remaining lifetime at 1-year increment was calculated using the life table method.
\end{abstract}

Results: Excerpts of the calculated expected remaining lifetimes of patients aged 60 years were as follows: 11.9 years for males and 14.1 years for females. These expected remaining lifetimes were 1.1 to 1.2 times as compared with those in 2003. Meanwhile, expected remaining lifetime of diabetic patients was 10.8 years for males and 12.5 years for females and that of nondiabetic patients was 13.0 years for males and 15.0 years for females.

Conclusion: Expected remaining lifetime of dialysis patients in Japan in 2015 was 10-20\% longer than that in 2003. These results suggest that advances in dialysis technologies during this 12-year period improved the survival rate of dialysis patients.

Keywords: Lifetime, Survival, Dialysis, Nationwide, Epidemiology

\section{Background}

The expected remaining lifetime of dialysis patients in Japan was published in 2003. According to the results, the expected remaining lifetime of dialysis patients in Japan was approximately half of that of the general population in Japan during the same period [1]. More than 15 years have passed since then. During this time, there have been several major advances in dialysis treatment. For example, new drugs, such as sustained erythropoiesis-stimulating agents, calcimimetics, calcium-free phosphate-binding

\footnotetext{
* Correspondence: s-nakai@fujita-hu.ac.jp

${ }^{1}$ Faculty of Clinical Engineering Technology, Fujita Health University School of Health Sciences, Dengakugakubo 1-98, Kutsukake-cho, Toyoake, Aichi 470-1192, Japan

Full list of author information is available at the end of the article
}

agents, and incretin-related agents, have been introduced to clinical use and are widely used [2-5]. Furthermore, quality control of dialysis fluid has greatly improved, and the number of online hemodialysis patients has dramatically increased [6]. From these, it is expected that the expected remaining lifetime of dialysis patients has been extended. On the other hand, diabetes can lead to systemic complications, and the survival prognosis is poor in dialysis patients with diabetic nephropathy as the primary disease [7, 8]. However, the 2003 report only reported the expected remaining lifetime of all dialysis patients and did not separately calculate the expected remaining lifetime of diabetic and nondiabetic patients [1].

This study aimed to determine the expected remaining lifetime of all dialysis patients at this time and to 
determine the expected remaining lifetime of diabetic and nondiabetic patients separately and to clarify whether the life prognosis of dialysis patients in Japan from 2003 to the present has improved or not.

\section{Methods}

The Japanese Society for Dialysis Therapy Renal Data Registry

The Japanese Society for Dialysis Therapy (JSDT) has conducted a statistical survey in all dialysis facilities in Japan. The survey consists of two investigations: a facility survey investigating the facility background and a patient survey investigating individual patients. In this patient survey, more than 900,000 patients have been registered in the database, including those who have died (JSDT Renal Data Registry, JRDR). The current analysis used the results from a patient survey conducted at the end of 2014 and the end of 2015 . The recovery rate based on the number of responding facilities was $96.0 \%$ at for the survey held as of the end of 2014 and $94.6 \%$ as of the end of $2015[6,9]$.

\section{Data collection}

With permission from the JSDT Statistical Survey Committee, the following statistical survey data were provided and used to calculate expected remaining lifetime. Initially, the number of age-stratified patients who were alive and underwent dialysis as of the end of 2014 (198, 125 males and 111,962 females) was obtained. These values can be interpreted as the number of patients alive at the start of 2015. Next, the number of age-stratified patients who were alive as of the end of $2015(179,649$ males and 101,758 females) was obtained from those who were alive and underwent dialysis at the end of 2014. Finally, the number of age-stratified patients who died by the end of 2015 (18,044 males and 111,417 females) was obtained from those who were alive and on dialysis as of the end of 2014. Information was missing from 432 males and 545 females. From the total number of age-stratified patients, patients' ages were stratified into 1-year increments.

\section{Calculating the expected remaining lifetime of dialysis patients}

The expected remaining lifetime of dialysis patients was calculated using the life table method [10], details of which are provided in the supplemental materials. Because there were very few patients below 30 years old or at 100 years old or older, expected remaining lifetime was calculated for every 1 year of age from 30 to 99 years.

Expected remaining lifetime was calculated separately for both sexes. Because the male-to-female ratio of patient number was different for each age group, the expected remaining lifetime of both sexes has been evaluated separately in the general population. Thus, the expected remaining lifetime of the total number of dialysis patients of both sexes was not calculated in this analysis.

Patients were divided into two groups according to the causes of renal failure: the diabetic group (patients with diabetic nephropathy) and the nondiabetic group (patients without diabetic nephropathy), and the expected remaining lifetime was calculated separately for both sexes in the two groups.

\section{Comparison with expected remaining lifetime in 2003}

The expected remaining lifetime of dialysis patients was compared between 2015 and 2003 [1]. The expected remaining lifetime of dialysis patients for every 10 years of age in 2015 and 2003 was excerpted, and the ratio of expected remaining lifetime in 2015 to that in 2003, referred to as historic year ratio (HY-R), was calculated. In addition, the difference in expected remaining lifetime (historic year difference, HY-D) between the 2 years, which was also used as an evaluation index, was also calculated.

\section{Comparison with the expected remaining lifetime of the general population}

The expected remaining lifetime of dialysis patients in 2015 was compared with the expected remaining lifetime of the general population in Japan in the same year. Values in the data released by the Ministry of Health, Labor and Welfare (MHLW) were used as the expected remaining lifetime of the general population [10]. Expected remaining lifetime for every 10 years of age of dialysis patients and the general population was extracted, and the ratio of the expected remaining lifetime of dialysis patients to that of the general population, referred to as dialysis patients to general population ratio (DG-R), was calculated. DG-R was also calculated for the expected remaining lifetime of dialysis patients in 2003 [1, 11].

\section{Comparison with the expected remaining lifetime of dialysis patients in Europe and the United States}

The expected remaining lifetime of dialysis patients in Japan was compared with that of patients in Europe and the United States (US) [12, 13]. However, the US report included only expected remaining lifetime based on survey data in 2014 and 2016 but not in 2015 [12, 14]. For this reason, the expected remaining lifetime of patients in the US was based on the 2016 survey data [12]. The expected remaining lifetime of dialysis patients in Europe was also based on the survey data during the 20112015 period and not the 2015 single-year data [13]. However, because single-year expected remaining lifetime of individuals in 2015 has not been published, this 
multiyear value was used for comparison. In addition, in the US and European reports, the expected remaining lifetime of patients was calculated every 5 years of age. For this reason, the median age in the 5-year age groups in Western reports was used to compare with the expected remaining lifetime of dialysis patients in Japan. The ratio of the expected remaining lifetime of patients in Japan to the obtained values of expected remaining lifetime of dialysis patients in Europe or the US, referred to as Japanese dialysis patients to US dialysis patients ratio (JU-R) or Japanese dialysis patients to European dialysis patients ratio (JE-R), was calculated.

\section{Comparison with the expected remaining lifetime of transplant patients in Europe and the US}

The expected remaining lifetime of dialysis patients in Japan was compared with that of transplant patients in Europe and the US. The abovementioned data used for comparison of the expected remaining lifetime of dialysis patients were used for the expected remaining lifetime values of transplant patients in Europe and the US [12, 13]. Comparison methods were as with the aforementioned methods used to compare the expected remaining lifetime of dialysis patients in Europe and the US. The ratio of the expected remaining lifetime of dialysis patients in Japan to that of transplant patients in Europe or the US, temporarily referred to as Japanese dialysis patients to US transplant patients ratio (JUT-R) or Japanese dialysis patients to European transplant patients ratio (JET-R), was calculated.

\section{Results}

Expected remaining lifetime of dialysis patients

Table 1 shows the expected remaining lifetime of dialysis patients in 2015 (the detailed data of this table is shown in Tables S1 and S2 of supplementary materials).

The expected remaining lifetime of males tended to be shorter than that of females. However, the expected remaining lifetime of males aged more than 90 years was inversely longer than that of females.

\section{Expected remaining lifetime of diabetic and nondiabetic patients}

The expected remaining lifetimes of diabetic and nondiabetic groups, which were separately calculated for both sexes, are presented in Tables 2 and 3, respectively (the detailed data of these tables are shown in Tables S3-S6 of the supplementary materials).

In both sexes, the expected remaining lifetime of diabetic patients tended to be shorter than that of nondiabetic patients. However, this tendency was weaker in

Table 1 Expected remaining lifetime of dialysis patients in Japan in 2015

\begin{tabular}{|c|c|c|c|c|c|c|c|c|c|c|c|}
\hline \multirow[t]{2}{*}{$\begin{array}{l}\text { Age } \\
\text { (years old) }\end{array}$} & \multicolumn{2}{|c|}{$\begin{array}{l}\text { Expected remaining } \\
\text { lifetime (years) }\end{array}$} & \multirow[t]{2}{*}{$\begin{array}{l}\text { Age } \\
\text { (years old) }\end{array}$} & \multicolumn{2}{|c|}{$\begin{array}{l}\text { Expected remaining } \\
\text { lifetime (years) }\end{array}$} & \multirow[t]{2}{*}{$\begin{array}{l}\text { Age } \\
\text { (years old) }\end{array}$} & \multicolumn{2}{|c|}{$\begin{array}{l}\text { Expected remaining } \\
\text { lifetime (years) }\end{array}$} & \multirow[t]{2}{*}{$\begin{array}{l}\text { Age } \\
\text { (years old) }\end{array}$} & \multicolumn{2}{|c|}{$\begin{array}{l}\text { Expected remaining } \\
\text { lifetime (years) }\end{array}$} \\
\hline & Male & Female & & Male & Female & & Male & Female & & Male & Female \\
\hline 30 & 30.8 & 34.1 & 50 & 17.3 & 20.4 & 70 & 7.7 & 8.9 & 90 & 2.4 & 2.2 \\
\hline 31 & 30.2 & 33.1 & 51 & 16.7 & 19.8 & 71 & 7.4 & 8.4 & 91 & 2.2 & 2.0 \\
\hline 32 & 29.5 & 32.5 & 52 & 16.0 & 19.1 & 72 & 7.0 & 8.0 & 92 & 2.0 & 1.9 \\
\hline 33 & 28.8 & 32.0 & 53 & 15.4 & 18.4 & 73 & 6.7 & 7.6 & 93 & 1.9 & 1.9 \\
\hline 34 & 28.4 & 31.2 & 54 & 14.9 & 17.8 & 74 & 6.3 & 7.1 & 94 & 2.0 & 1.6 \\
\hline 35 & 27.5 & 30.6 & 55 & 14.5 & 17.1 & 75 & 6.0 & 6.7 & 95 & 1.7 & 1.2 \\
\hline 36 & 26.8 & 30.0 & 56 & 14.0 & 16.6 & 76 & 5.8 & 6.4 & 96 & 1.6 & 1.4 \\
\hline 37 & 25.9 & 29.1 & 57 & 13.5 & 16.0 & 77 & 5.5 & 6.0 & 97 & 1.2 & 1.2 \\
\hline 38 & 25.4 & 28.4 & 58 & 12.9 & 15.4 & 78 & 5.2 & 5.7 & 98 & 0.9 & 0.9 \\
\hline 39 & 24.7 & 27.6 & 59 & 12.4 & 14.8 & 79 & 4.9 & 5.4 & 99 & 0.5 & 0.5 \\
\hline 40 & 23.9 & 26.9 & 60 & 11.9 & 14.1 & 80 & 4.6 & 5.0 & & & \\
\hline 41 & 23.0 & 26.3 & 61 & 11.4 & 13.5 & 81 & 4.3 & 4.8 & & & \\
\hline 42 & 22.2 & 25.6 & 62 & 10.9 & 12.9 & 82 & 4.0 & 4.5 & & & \\
\hline 43 & 21.5 & 24.9 & 63 & 10.4 & 12.3 & 83 & 3.7 & 4.1 & & & \\
\hline 44 & 20.9 & 24.2 & 64 & 10.0 & 11.7 & 84 & 3.5 & 3.8 & & & \\
\hline 45 & 20.3 & 23.6 & 65 & 9.6 & 11.1 & 85 & 3.3 & 3.6 & & & \\
\hline 46 & 19.7 & 22.9 & 66 & 9.1 & 10.5 & 86 & 3.1 & 3.3 & & & \\
\hline 47 & 19.1 & 22.3 & 67 & 8.6 & 10.0 & 87 & 2.9 & 3.1 & & & \\
\hline 48 & 18.5 & 21.7 & 68 & 8.2 & 9.5 & 88 & 2.7 & 2.8 & & & \\
\hline 49 & 17.9 & 21.2 & 69 & 8.0 & 9.3 & 89 & 2.4 & 2.5 & & & \\
\hline
\end{tabular}


Table 2 Expected remaining lifetime of dialysis patients with diabetes in Japan in 2015

\begin{tabular}{|c|c|c|c|c|c|c|c|c|c|c|c|}
\hline \multirow[t]{2}{*}{$\begin{array}{l}\text { Age } \\
\text { (years old) }\end{array}$} & \multicolumn{2}{|c|}{$\begin{array}{l}\text { Expected } \\
\text { remaining } \\
\text { lifetime (years) }\end{array}$} & \multirow[t]{2}{*}{$\begin{array}{l}\text { Age } \\
\text { (years old) }\end{array}$} & \multicolumn{2}{|c|}{$\begin{array}{l}\text { Expected } \\
\text { remaining } \\
\text { lifetime (years) }\end{array}$} & \multirow[t]{2}{*}{$\begin{array}{l}\text { Age } \\
\text { (years old) }\end{array}$} & \multicolumn{2}{|c|}{$\begin{array}{l}\text { Expected } \\
\text { remaining } \\
\text { lifetime (years) }\end{array}$} & \multirow[t]{2}{*}{$\begin{array}{l}\text { Age } \\
\text { (years old) }\end{array}$} & \multicolumn{2}{|c|}{$\begin{array}{l}\text { Expected } \\
\text { remaining } \\
\text { lifetime (years) }\end{array}$} \\
\hline & Male & Female & & Male & Female & & Male & Female & & Male & Female \\
\hline 30 & 27.1 & 31.0 & 50 & 15.4 & 17.8 & 70 & 7.1 & 8.0 & 90 & 2.1 & 2.2 \\
\hline 31 & 26.1 & 30.0 & 51 & 14.9 & 17.4 & 71 & 6.8 & 7.6 & 91 & 2.0 & 2.1 \\
\hline 32 & 25.1 & 29.0 & 52 & 14.3 & 16.6 & 72 & 6.5 & 7.2 & 92 & 1.7 & 2.0 \\
\hline 33 & 24.1 & 28.0 & 53 & 13.8 & 16.0 & 73 & 6.2 & 6.9 & 93 & 1.5 & 2.0 \\
\hline 34 & 24.9 & 27.0 & 54 & 13.4 & 15.5 & 74 & 5.9 & 6.5 & 94 & 1.8 & 1.5 \\
\hline 35 & 24.3 & 26.9 & 55 & 12.9 & 15.0 & 75 & 5.7 & 6.1 & 95 & 1.4 & 1.0 \\
\hline 36 & 23.9 & 25.9 & 56 & 12.6 & 14.6 & 76 & 5.4 & 5.8 & 96 & 1.5 & 1.3 \\
\hline 37 & 23.2 & 24.9 & 57 & 12.2 & 14.2 & 77 & 5.1 & 5.5 & 97 & 1.3 & 1.4 \\
\hline 38 & 22.3 & 24.4 & 58 & 11.6 & 13.6 & 78 & 4.9 & 5.2 & 98 & 0.8 & 0.8 \\
\hline 39 & 22.0 & 23.4 & 59 & 11.2 & 13.0 & 79 & 4.6 & 4.9 & 99 & 0.5 & 0.5 \\
\hline 40 & 21.4 & 22.4 & 60 & 10.8 & 12.5 & 80 & 4.3 & 4.7 & & & \\
\hline 41 & 20.4 & 21.8 & 61 & 10.3 & 11.8 & 81 & 4.0 & 4.6 & & & \\
\hline 42 & 19.8 & 21.2 & 62 & 9.9 & 11.4 & 82 & 3.7 & 4.3 & & & \\
\hline 43 & 19.2 & 20.5 & 63 & 9.5 & 10.9 & 83 & 3.5 & 3.9 & & & \\
\hline 44 & 18.8 & 20.0 & 64 & 9.0 & 10.4 & 84 & 3.2 & 3.7 & & & \\
\hline 45 & 18.2 & 19.6 & 65 & 8.7 & 10.0 & 85 & 3.0 & 3.5 & & & \\
\hline 46 & 17.7 & 19.1 & 66 & 8.3 & 9.5 & 86 & 2.7 & 3.3 & & & \\
\hline 47 & 17.1 & 18.8 & 67 & 7.9 & 8.9 & 87 & 2.6 & 3.1 & & & \\
\hline 48 & 16.5 & 18.7 & 68 & 7.5 & 8.5 & 88 & 2.3 & 2.9 & & & \\
\hline 49 & 16.1 & 18.2 & 69 & 7.4 & 8.2 & 89 & 2.2 & 2.5 & & & \\
\hline
\end{tabular}

both sexes aged 70 years or older. In particular, the expected remaining lifetime of 90 -year-old females in the diabetic group was almost equal to that in the nondiabetic group.

\section{Comparison with expected remaining lifetime in 2003}

HY-R ranged from 1.1 to 1.2 in almost all age groups in both sexes, i.e., the expected remaining lifetime in 2015 increased by $10-20 \%$ to that in 2003 in almost all age groups for both sexes (Table 4). However, at the age of 90 years, both values were almost equivalent.

HY-D at the age of 30 years was 3.41 years for males and 3.78 years for females, showing differences of more than 3 years for both sexes. However, HY-D was shortened with age, and almost no differences were observed between 2013 and 2015 at 90 years of age.

\section{Comparison with the expected remaining lifetime of the general population}

In both sexes, the DG-R tended to decrease with age, i.e., the handicap in dialysis patients against the general population showed a tendency to increase with age (Table 5). This tendency was stronger in females than in males. Similar trends were observed in 2003 values $[1,10]$.
Conversely, DG-R in 2015 was higher than that in 2003 at all ages for both sexes. The results suggest that the handicap in dialysis patients on survival prognosis against the general population was more reduced in 2015 than in 2003. However, only in female patients aged 90 years that DG-R in 2015 was lower than that in 2003.

To analyze the background under which DG-R was reduced more in older female patients in 2015, DG-R was calculated for every 1 year of age for patients aged 80 to 99 years. This calculation was performed for a total of six groups: diabetic group, nondiabetic group, and combined group (the group of total dialysis patients) for both sexes. The expected remaining lifetime of the general population used for DG-R calculation was the same as that of patients of the same age and sex (Fig. 1). In female nondiabetic dialysis patients aged 80 years or older, DG-R showed a tendency to decrease with age. No such tendency was necessarily observed in diabetic patients for both sexes.

\section{Comparison with the expected remaining lifetime of dialysis patients in Europe and the US}

JU-R and JE-R (ratio of the expected remaining lifetime of patients in Japan to that in Europe or the US) are shown in Table 6. JU-R was 1.5- to 2.1-fold in males and 1.5- to 2.6-fold in females. Conversely, JE-R was 1.4- to 1.9-fold 
Table 3 Expected remaining lifetime of dialysis patients without diabetes in Japan in 2015

\begin{tabular}{|c|c|c|c|c|c|c|c|c|c|c|c|}
\hline \multirow[t]{2}{*}{$\begin{array}{l}\text { Age } \\
\text { (years old) }\end{array}$} & \multicolumn{2}{|c|}{$\begin{array}{l}\text { Expected } \\
\text { remaining } \\
\text { lifetime (years) }\end{array}$} & \multirow[t]{2}{*}{$\begin{array}{l}\text { Age } \\
\text { (years old) }\end{array}$} & \multicolumn{2}{|c|}{$\begin{array}{l}\text { Expected } \\
\text { remaining } \\
\text { lifetime (years) }\end{array}$} & \multirow[t]{2}{*}{$\begin{array}{l}\text { Age } \\
\text { (years old) }\end{array}$} & \multicolumn{2}{|c|}{$\begin{array}{l}\text { Expected } \\
\text { remaining } \\
\text { lifetime (years) }\end{array}$} & \multirow[t]{2}{*}{$\begin{array}{l}\text { Age } \\
\text { (years old) }\end{array}$} & \multicolumn{2}{|c|}{$\begin{array}{l}\text { Expected } \\
\text { remaining } \\
\text { lifetime (years) }\end{array}$} \\
\hline & Male & Female & & Male & Female & & Male & Female & & Male & Female \\
\hline 30 & 33.3 & 35.8 & 50 & 19.1 & 21.8 & 70 & 8.2 & 9.4 & 90 & 2.5 & 2.2 \\
\hline 31 & 32.9 & 34.8 & 51 & 18.4 & 21.1 & 71 & 7.8 & 8.9 & 91 & 2.3 & 2.0 \\
\hline 32 & 32.3 & 34.3 & 52 & 17.7 & 20.4 & 72 & 7.4 & 8.4 & 92 & 2.1 & 1.8 \\
\hline 33 & 31.6 & 33.9 & 53 & 17.0 & 19.7 & 73 & 7.0 & 7.9 & 93 & 2.0 & 1.8 \\
\hline 34 & 30.9 & 33.2 & 54 & 16.4 & 19.0 & 74 & 6.6 & 7.4 & 94 & 2.1 & 1.6 \\
\hline 35 & 29.9 & 32.5 & 55 & 15.9 & 18.2 & 75 & 6.3 & 7.0 & 95 & 1.8 & 1.3 \\
\hline 36 & 29.1 & 31.9 & 56 & 15.3 & 17.6 & 76 & 6.0 & 6.7 & 96 & 1.6 & 1.4 \\
\hline 37 & 28.2 & 31.2 & 57 & 14.7 & 17.0 & 77 & 5.7 & 6.3 & 97 & 1.2 & 1.2 \\
\hline 38 & 27.8 & 30.3 & 58 & 14.0 & 16.3 & 78 & 5.4 & 5.9 & 98 & 0.9 & 0.9 \\
\hline 39 & 27.0 & 29.6 & 59 & 13.5 & 15.7 & 79 & 5.1 & 5.6 & 99 & 0.5 & 0.5 \\
\hline 40 & 26.1 & 29.0 & 60 & 13.0 & 15.0 & 80 & 4.7 & 5.2 & & & \\
\hline 41 & 25.2 & 28.4 & 61 & 12.4 & 14.4 & 81 & 4.5 & 5.0 & & & \\
\hline 42 & 24.4 & 27.7 & 62 & 11.9 & 13.7 & 82 & 4.1 & 4.6 & & & \\
\hline 43 & 23.6 & 27.1 & 63 & 11.4 & 13.0 & 83 & 3.8 & 4.3 & & & \\
\hline 44 & 22.9 & 26.2 & 64 & 10.9 & 12.4 & 84 & 3.6 & 3.9 & & & \\
\hline 45 & 22.3 & 25.4 & 65 & 10.3 & 11.8 & 85 & 3.4 & 3.6 & & & \\
\hline 46 & 21.5 & 24.8 & 66 & 9.9 & 11.1 & 86 & 3.3 & 3.3 & & & \\
\hline 47 & 21.0 & 24.0 & 67 & 9.3 & 10.6 & 87 & 3.0 & 3.1 & & & \\
\hline 48 & 20.3 & 23.2 & 68 & 8.9 & 10.1 & 88 & 2.8 & 2.8 & & & \\
\hline 49 & 19.7 & 22.6 & 69 & 8.6 & 9.9 & 89 & 2.5 & 2.4 & & & \\
\hline
\end{tabular}

in males and 1.4- to 2.1-fold in females. In both Europe and the US, the differences between both sexes were larger in the younger age group, and the differences tended to decrease in the older age group.

\section{Comparison with the expected remaining lifetime of transplant patients in Europe and the US}

JUT-R and JET-R (ratio of the expected remaining lifetime of dialysis patients in Japan to that of transplant patients in Europe or the US) are shown in Table 7. JUT-R was approximately 0.8 -fold in males and 0.8 - to 0.9 -fold in females. Conversely, JET-R was approximately 0.9fold in males and 0.9- to 1.0-fold in females.

\section{Discussion}

The JSDT patient surveys in 2014 and 2015 used in this analysis showed high response rates of $96.0 \%$ and $94.6 \%$, respectively [6,9]. The survey response rates in 2002 and 2003 used to calculate the expected remaining lifetime in 2003 were $96.8 \%$ and $96.6 \%$, respectively,

Table 4 Comparison of the expected remaining lifetime between males and females or between the years 2015 and 2003 (excerpts every 10 years)

\begin{tabular}{|c|c|c|c|c|c|c|c|c|}
\hline \multirow{3}{*}{$\begin{array}{l}\text { Age }^{a} \\
\text { (years old) }\end{array}$} & \multirow{2}{*}{\multicolumn{2}{|c|}{$\begin{array}{l}2015 \\
\text { Expected remaining lifetime (years) }\end{array}$}} & \multirow{2}{*}{\multicolumn{2}{|c|}{$\begin{array}{l}2003 \\
\text { Expected remaining lifetime (years) [1] }\end{array}$}} & \multicolumn{2}{|c|}{ HY-R } & \multicolumn{2}{|c|}{ HY-D ${ }^{c}$} \\
\hline & & & & & \multirow[t]{2}{*}{ Male } & \multirow[t]{2}{*}{ Female } & \multirow[t]{2}{*}{ Male } & \multirow[t]{2}{*}{ Female } \\
\hline & Male & Female & Male & Female & & & & \\
\hline 30 & 30.8 & 34.1 & 27.4 & 30.3 & 1.12 & 1.12 & 3.41 & 3.78 \\
\hline 40 & 23.9 & 26.9 & 20.5 & 23.2 & 1.16 & 1.16 & 3.38 & 3.69 \\
\hline 50 & 17.3 & 20.4 & 14.6 & 16.7 & 1.19 & 1.22 & 2.73 & 3.68 \\
\hline 60 & 11.9 & 14.1 & 9.9 & 11.3 & 1.20 & 1.25 & 2.01 & 2.79 \\
\hline 70 & 7.7 & 8.9 & 6.2 & 7.1 & 1.24 & 1.25 & 1.48 & 1.78 \\
\hline 80 & 4.6 & 5.0 & 3.8 & 4.4 & 1.20 & 1.14 & 0.74 & 0.62 \\
\hline 90 & 2.4 & 2.2 & 2.3 & 2.6 & 1.02 & 0.86 & 0.04 & -0.35 \\
\hline
\end{tabular}

${ }^{a}$ The expected remaining lifetime at each age was excerpted every 10 years

${ }^{b} \mathrm{HY}-\mathrm{R}=$ (expected remaining lifetime in 2015) $\div$ (expected remaining lifetime in 2003)

${ }^{c} \mathrm{HY}-\mathrm{D}=$ (expected remaining lifetime in 2015) - (expected remaining lifetime in 2003) 
Table 5 Comparison of the expected remaining lifetime between dialysis patients and the general population (excerpts every 10 years)

\begin{tabular}{|c|c|c|c|c|c|c|c|c|c|c|c|c|}
\hline \multirow[t]{2}{*}{$\begin{array}{l}\mathrm{Age}^{\mathrm{a}} \\
\text { (years old) }\end{array}$} & \multicolumn{2}{|c|}{$\begin{array}{l}\text { Expected remaining } \\
\text { lifetime of dialysis } \\
\text { patients (2015) }\end{array}$} & \multicolumn{2}{|c|}{$\begin{array}{l}\text { Expected remaining } \\
\text { lifetime of Japanese } \\
\text { general population } \\
(2015) \text { [10] }\end{array}$} & \multicolumn{2}{|c|}{ DG-R ${ }^{b}(2015)$} & \multicolumn{2}{|c|}{$\begin{array}{l}\text { Expected remaining } \\
\text { lifetime of dialysis } \\
\text { patients (2003) [1] }\end{array}$} & \multicolumn{2}{|c|}{$\begin{array}{l}\text { Expected remaining } \\
\text { lifetime of Japanese } \\
\text { general population } \\
\text { (2003) [11] }\end{array}$} & \multicolumn{2}{|c|}{ DG-R ${ }^{b}(2003)$} \\
\hline & Male & Female & Male & Female & Male & Female & Male & Female & Male & Female & Male & Female \\
\hline 30 & 30.8 & 34.1 & 51.5 & 57.5 & 0.60 & 0.59 & 27.4 & 30.3 & 49.2 & 56.0 & 0.56 & 0.54 \\
\hline 40 & 23.9 & 26.9 & 41.8 & 47.7 & 0.57 & 0.56 & 20.5 & 23.2 & 39.7 & 46.2 & 0.52 & 0.50 \\
\hline 50 & 17.3 & 20.4 & 32.4 & 38.1 & 0.53 & 0.54 & 14.6 & 16.7 & 30.5 & 36.7 & 0.48 & 0.46 \\
\hline 60 & 11.9 & 14.1 & 23.6 & 28.8 & 0.50 & 0.49 & 9.9 & 11.3 & 22.0 & 27.5 & 0.45 & 0.41 \\
\hline 70 & 7.7 & 8.9 & 15.6 & 19.9 & 0.49 & 0.45 & 6.2 & 7.1 & 14.4 & 18.8 & 0.43 & 0.38 \\
\hline 80 & 4.6 & 5.0 & 8.9 & 11.8 & 0.51 & 0.43 & 3.8 & 4.4 & 8.3 & 11.0 & 0.46 & 0.40 \\
\hline 90 & 2.4 & 2.2 & 4.4 & 5.7 & 0.54 & 0.39 & 2.3 & 2.6 & 4.3 & 5.6 & 0.55 & 0.46 \\
\hline
\end{tabular}

${ }^{a}$ The expected remaining lifetime at each age was excerpted every 10 years

${ }^{b} \mathrm{DG}-\mathrm{R}=$ (expected remaining lifetime of dialysis patients) $\div$ (expected remaining lifetime in the general population)

comparable to those obtained in this study $[15,16]$. Thus, the expected remaining lifetime in 2015 and 2003 calculated in this study both seem to be interpretable as actual conditions of the expected remaining lifetime of dialysis patients in Japan.

The expected remaining lifetime of dialysis patients in 2015 improved compared with that in 2003 for almost all ages in both sexes (Table 4). In addition, DG-R was higher in 2015 than in 2003 at all ages in both sexes. These results suggest that survival prognosis of dialysis patients improved between 2003 and 2015. Here, the proportion of diabetics in dialysis patients in 2003 was $29.2 \%$ and $38.4 \%$ in 2015 [6, 16], i.e., the proportion of diabetic patients in all dialysis patients increased by about 9 points in this 12-year period. Diabetic dialysis patients are known to have a worse survival prognosis than nondiabetic dialysis patients $[7,8]$. Thus, the present findings that the expected remaining lifetime of dialysis patients in 2015 improved despite an increase in diabetic patients with a disadvantage in survival prognosis may reflect advances in medical technologies during this 12-year period. We attempted to calculate HY-R for dialysis patients in Europe and the US and found that the expected remaining lifetime of dialysis patients in Europe and the US has improved by $20-30 \%$ in the last 12 years (see Tables S7 and S8 in the supplementary materials) $[12,13,17,18]$. This indicates an improvement in the survival rate of dialysis patients as a worldwide trend. Between 2003 and 2015, there have been numerous developments in medical technologies related to dialysis treatment. Calcium-free phosphorus adsorbents were launched in 2003 [2], sustained erythropoiesis-
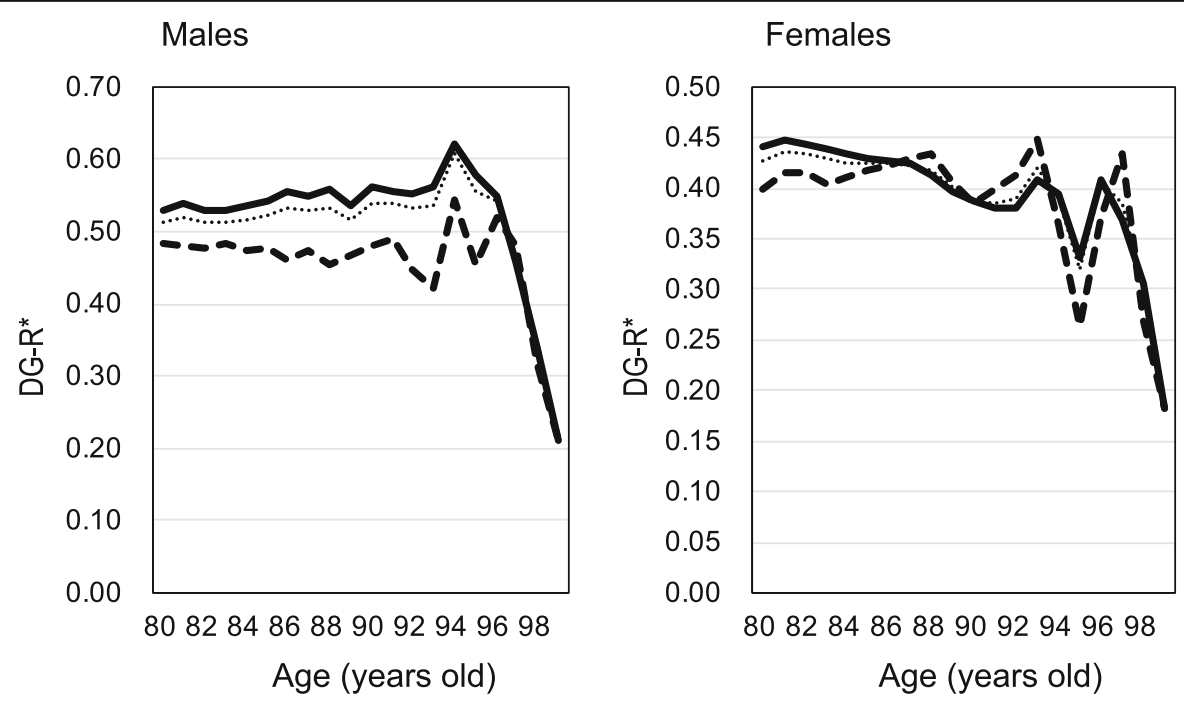

........ Total $\mathbf{-}$ - D Dlabetes $\longrightarrow$-diabetes

Fig. 1 Detailed comparisons of the expected remaining lifetime between dialysis patients and the general population (from age 80 to 99 years). ${ }^{*} \mathrm{DG}-\mathrm{R}=$ (expected remaining lifetime of dialysis patients) $\div$ (expected remaining lifetime in the general population) 
Table 6 Comparison of the expected remaining lifetime of dialysis patients between Japan, the US, and Europe [12, 13]

\begin{tabular}{|c|c|c|c|c|c|c|c|c|c|c|c|}
\hline \multirow[t]{2}{*}{$\begin{array}{l}\text { Age }^{a} \\
\text { (years old) }\end{array}$} & \multicolumn{2}{|c|}{$\begin{array}{l}\text { Expected } \\
\text { remaining lifetime } \\
\text { of Japanese dialysis } \\
\text { patients (years, 2015) }\end{array}$} & \multicolumn{3}{|c|}{$\begin{array}{l}\text { Expected remaining } \\
\text { lifetime of US } \\
\text { dialysis patients } \\
\text { (years, 2016) [12] }\end{array}$} & \multicolumn{2}{|l|}{$J U-R^{b}$} & \multicolumn{2}{|c|}{$\begin{array}{l}\text { Expected remaining } \\
\text { lifetime of European } \\
\text { dialysis patients (years, } \\
2011 \sim 2015 \text { ) [13] }\end{array}$} & \multicolumn{2}{|l|}{$J E-R^{c}$} \\
\hline & Male & Female & Age & Male & Female & Male & Female & Male & Female & Male & Female \\
\hline 32 & 29.5 & 32.5 & $30-34$ & 14.1 & 12.7 & 2.09 & 2.56 & 16.1 & 16.2 & 1.83 & 2.01 \\
\hline 37 & 25.9 & 29.1 & $35-39$ & 12.4 & 11.4 & 2.09 & 2.56 & 13.9 & 14.1 & 1.87 & 2.07 \\
\hline 42 & 22.2 & 25.6 & $40-44$ & 11.0 & 10.2 & 2.02 & 2.51 & 11.8 & 12.2 & 1.88 & 2.10 \\
\hline 47 & 19.1 & 22.3 & $45-49$ & 9.3 & 8.7 & 2.05 & 2.56 & 9.9 & 10.6 & 1.93 & 2.10 \\
\hline 52 & 16.0 & 19.1 & $50-54$ & 7.9 & 7.6 & 2.03 & 2.51 & 8.3 & 8.9 & 1.93 & 2.14 \\
\hline 57 & 13.5 & 16.0 & $55-59$ & 6.7 & 6.6 & 2.01 & 2.43 & 7.0 & 7.5 & 1.92 & 2.14 \\
\hline 62 & 10.9 & 12.9 & $60-64$ & 5.6 & 5.7 & 1.95 & 2.26 & 6.0 & 6.5 & 1.82 & 1.98 \\
\hline 67 & 8.6 & 10.0 & $65-69$ & 4.6 & 4.8 & 1.88 & 2.08 & 5.2 & 5.6 & 1.66 & 1.78 \\
\hline 72 & 7.0 & 8.0 & 70-74 & 3.8 & 4.1 & 1.84 & 1.94 & 4.6 & 4.8 & 1.52 & 1.66 \\
\hline 77 & 5.5 & 6.0 & 75-79 & 3.3 & 3.6 & 1.66 & 1.68 & 3.9 & 4.1 & 1.41 & 1.47 \\
\hline 82 & 4.0 & 4.5 & $80-84$ & 2.7 & 3.0 & 1.48 & 1.50 & 3.3 & 3.3 & 1.21 & 1.36 \\
\hline 87 & 2.9 & 3.1 & $85-89$ & - & - & - & - & 2.1 & 2.2 & 1.38 & 1.39 \\
\hline
\end{tabular}

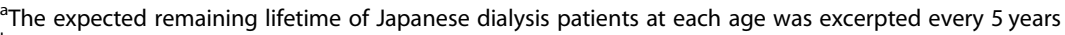

bJU-R = (expected remaining lifetime of dialysis patients in Japan) $\div$ (expected remaining lifetime of dialysis patients in the US)

${ }^{\mathrm{C}} \mathrm{JE}-\mathrm{R}=$ (expected remaining lifetime of dialysis patients in Japan) $\div$ (expected remaining lifetime of dialysis patients in Europe)

stimulating agents in 2007 [3], and calcimimetics in 2008 [4]. The present results cannot clarify the cause of the improvement in survival prognosis. However, the clinical use of these drugs for dialysis patients may be related to the improvement in the expected remaining lifetime of dialysis patients. Between 2003 and 2015, incretin-related drugs also became available for clinical use [5]. This situation may have contributed to an improvement in the survival of diabetic patients. However, we could not evaluate whether the expected remaining lifetime of the diabetic group was improved more than that of the nondiabetic group because the expected remaining lifetime of dialysis patients in 2003 had not been reported [1]. HY-D between 2015 and 2003 was larger in younger patients than in older patients (Table 4). This indicates that the absolute magnitude of improvements in expected remaining lifetime is larger in younger patients than in older patients.

Table 7 Comparison of the expected remaining lifetime of dialysis or transplant patients between Japan, the US, and Europe [12, 13]

\begin{tabular}{|c|c|c|c|c|c|c|c|c|c|c|c|}
\hline \multirow[t]{2}{*}{$\begin{array}{l}\text { Age }^{a} \\
\text { (years old) }\end{array}$} & \multicolumn{2}{|c|}{$\begin{array}{l}\text { Expected remaining } \\
\text { lifetime of Japanese } \\
\text { dialysis patients } \\
\text { (years, 2015) }\end{array}$} & \multicolumn{3}{|c|}{$\begin{array}{l}\text { Expected remaining } \\
\text { lifetime of US transplant } \\
\text { patients (years, 2016) [12] }\end{array}$} & \multicolumn{2}{|c|}{ JUT-R ${ }^{b}$} & \multicolumn{2}{|c|}{$\begin{array}{l}\text { Expected remaining } \\
\text { lifetime of European } \\
\text { transplant patients } \\
\text { (years, 2011 2015) [13] }\end{array}$} & \multicolumn{2}{|l|}{ JET-R } \\
\hline & Male & Female & Age & Male & Female & Male & Female & Male & Female & Male & Female \\
\hline 32 & 29.5 & 32.5 & $30-34$ & 35.3 & 37.1 & 0.84 & 0.88 & 34.2 & 35.4 & 0.86 & 0.92 \\
\hline 37 & 25.9 & 29.1 & $35-39$ & 31.2 & 33.1 & 0.83 & 0.88 & 30.1 & 31.2 & 0.86 & 0.93 \\
\hline 42 & 22.2 & 25.6 & $40-44$ & 27.4 & 29.1 & 0.81 & 0.88 & 26 & 27.4 & 0.86 & 0.93 \\
\hline 47 & 19.1 & 22.3 & $45-49$ & 23.6 & 25.2 & 0.81 & 0.88 & 22.3 & 23.7 & 0.86 & 0.94 \\
\hline 52 & 16.0 & 19.1 & $50-54$ & 20.0 & 21.7 & 0.80 & 0.88 & 18.5 & 19.9 & 0.87 & 0.96 \\
\hline 57 & 13.5 & 16.0 & $55-59$ & 16.8 & 18.2 & 0.80 & 0.88 & 15.4 & 16.5 & 0.87 & 0.97 \\
\hline 62 & 10.9 & 12.9 & $60-64$ & 14.0 & 15.2 & 0.78 & 0.85 & 12.4 & 13.3 & 0.88 & 0.97 \\
\hline 67 & 8.6 & 10.0 & $65-69$ & 11.4 & 12.5 & 0.76 & 0.80 & 9.9 & 10.5 & 0.87 & 0.95 \\
\hline 72 & 7.0 & 8.0 & $70-74$ & 9.3 & 10.1 & 0.75 & 0.79 & 7.6 & 7.9 & 0.92 & 1.01 \\
\hline 77 & 5.5 & 6.0 & $75-79$ & - & - & - & - & 5.6 & 5.5 & 0.98 & 1.10 \\
\hline 82 & 4.0 & 4.5 & $80-84$ & - & - & - & - & 3.6 & 3.3 & 1.11 & 1.36 \\
\hline
\end{tabular}

${ }^{a}$ The expected remaining lifetime of Japanese dialysis patients at each age was excerpted every 5 years

bJUT-R = (expected remaining lifetime of dialysis patients in Japan) $\div$ (expected remaining lifetime of transplant patients in the US)

${ }^{\mathrm{C} J E T-R}=$ (expected remaining lifetime of dialysis patients in Japan) $\div$ (expected remaining lifetime of transplant patients in Europe) 
The expected remaining lifetime of male patients tended to be shorter than that of females almost in all ages. This phenomenon is also observed in both of diabetic and nondiabetic groups. These suggest that sex differences in survival prognosis of dialysis patients are independent of aging and the presence of diabetes. It has already been pointed out that survival prognosis of dialysis patients is better for females than males, which is in line with the present results $[7,8]$. The expected remaining lifetime of the general population is also longer for females than for males [10]. This suggests that sex difference in survival prognosis of dialysis patients is an influencing factor independent of renal failure. But in the general population aged 70 years or older, the expected remaining lifetime of males decreased more than that of female [10]. This indicates that in the general population, sex differences in survival prognosis increase at age 70 years or older. Conversely, no such findings were observed in the expected remaining lifetime of dialysis patients. This suggests that the handicap in dialysis patients on survival prognosis against the general population increases in older females (Table 5). This trend was more pronounced in female nondiabetic patients aged 80 years and older (Fig. 1). These results suggest that adverse effects associated with renal failure on survival prognosis are more pronounced in nondiabetic older females. However, we could not reveal the background of this finding based on this study results.

The comparison between diabetic and nondiabetic groups showed that the expected remaining lifetime of the diabetic group was approximately $80-90 \%$ of that of the nondiabetic group in all age groups for both sexes. It has been already known that survival prognosis of dialysis patients with diabetes is poor, which is consistent with our results $[7,8]$.

The expected remaining lifetime of dialysis patients in Japan is almost twice that of patients in Europe and the US. It has already been pointed out that survival prognosis of dialysis patients in Japan is superior to that in dialysis patients in Europe and the US, which is consistent with the present results [19].

The expected remaining lifetime of dialysis patients in Japan was 0.8- to 0.9-fold that of transplant patients in Europe and the US. These results indicate that survival prognosis of dialysis patients in Japan is approaching the survival prognosis of transplant patients in Europe and the US. However, the expected remaining lifetime of kidney transplant patients in Japan has not been reported and could not be compared.

This study has several limitations. First, because there were very few patients aged $<30$ years and $\geq 100$ years, expected remaining lifetime could not be calculated with reliable precision. Second, the dialysis vintage was not taken into consideration in calculating mean values of expected remaining lifetime. For example, when the expected remaining lifetime of 60-year-old dialysis patients was estimated, patients who had been undergoing dialysis for 1 year were not distinguished from those who had been on dialysis for 20 years in the calculation. Therefore, there are certain errors due to differences in dialysis vintage between the mean length of expected remaining lifetime calculated in this study and the expected remaining lifetime of each patient. Nevertheless, even without taking differences in dialysis vintage into consideration, age-specific mean lengths of expected remaining lifetime calculated for patients undergoing chronic dialysis at a certain time point have clinical significance as an indicator of the survival prognosis of dialysis patients. In fact, the age-specific expected remaining lifetime data in annual reports of the USRDS and ERAEDTA are calculated with no regard to dialysis vintage, albeit the method used for estimating expected remaining lifetime was different from that used in this study $[12,13]$. Third, the expected remaining lifetime of patients aged 90 years or older may contain large errors due to the large variation in DG-R for both sexes in the age group of 90 years or older (Fig. 1). Fourth, there was a methodological limitation as comparison between the USRDS/ERA-EDTAreported mean expected remaining lifetime in Western countries and our data. The method of estimating the survival function used for calculation of mean expected remaining lifetime values reported by the USRDS and ERA-EDTA was different from that used in this study [12, 13]. In addition, age categories of mean expected remaining lifetime estimates and periods to be included in calculation were also different. Therefore, expected remaining lifetime estimates reported by the USRDS/ERA-EDTA and those calculated in this study may differ to a certain extent because of these methodological differences, and caution should be exercised when comparing these values and interpreting the results of comparison.

\section{Conclusion}

Expected remaining lifetime of dialysis patients in Japan in 2015 was $10-20 \%$ longer than that in 2003 . These results suggest that advances in dialysis technologies during this 12-year period improved the survival rate of dialysis patients.

\section{Supplementary Information}

The online version contains supplementary material available at https://doi. org/10.1186/s41100-020-00301-z

Additional file 1: Methods for calculating expected remaining lifetime. Tables S1 and S2. The expected remaining lifetime of Japanese dialysis patients (2015). Tables S3 and S4. The expected remaining lifetime of the patients the diabetic group (2015). Tables S5 and S6. The expected remaining lifetime of the patients in the nondiabetic group (2015). Table S7. Comparison of the expected remaining lifetime of patients in the United States between 2003 and 2016. Table S8. Comparison of the expected remaining lifetime of dialysis patients in Europe between 2003 and 2011-2015. 


\section{Abbreviations}

DG-R: The ratio of the expected remaining lifetime of dialysis patients to that of the general population, referred to as dialysis patients to general population ratio; HY-D: The difference in expected remaining lifetime between the 2 years of 2015 and 2003, referred to as historic year difference; HY-R: The ratio of expected remaining lifetime in 2015 to that in 2003, referred to as historic year ratio; JE-R: The ratio of the expected remaining lifetime of patients in Japan to the obtained values of expected remaining lifetime of dialysis patients in Europe, referred to as Japanese dialysis patients to European dialysis patients ratio; JET-R: The ratio of the expected remaining lifetime of dialysis patients in Japan to that of transplant patients in Europe temporarily referred to as Japanese dialysis patients to European transplant patients ratio; JRDR: Japanese Society for Dialysis Therapy Renal Data Registry; JSDT: Japanese Society for Dialysis Therapy; JU-R: The ratio of the expected remaining lifetime of patients in Japan to the obtained values of expected remaining lifetime of dialysis patients in the US, referred to as Japanese dialysis patients to US dialysis patients ratio; JUT-R: The ratio of the expected remaining lifetime of dialysis patients in Japan to that of transplant patients in the US, temporarily referred to as Japanese dialysis patients to US transplant patients ratio; MHLW: Ministry of Health, Labor and Welfare; US: United States

\section{Acknowledgements}

The data that support the findings of this study are available from JSDT, but restrictions apply to the availability of these data, which were used under license for the current study. Therefore, they are not publicly available. Data are however available from the authors upon reasonable request and with permission from JSDT.

\section{Authors' contributions}

S.N. and K.W. devised the study design. S.N. and A.W. analyzed the data. M.A. and K.N. assisted with the epidemiological assessment. S.N. wrote the original draft, prepared the tables and figures, and searched the literature. All authors interpreted the data and reviewed the manuscript. The author(s) read and approved the final manuscript.

\section{Funding}

The authors did not receive any funding for this study.

\section{Availability of data and materials}

The data that support the findings of this study are available from JSDT but restrictions apply to the availability of these data, which were used under license for the current study, and so are not publicly available. Data are however available from the authors upon reasonable request and with permission of JSDT.

\section{Ethics approval and consent to participate}

JRDR was approved by the ethical committee of JSDT (approval number 1-3) and has been registered in "University hospital Medical Information Network (UMIN) Clinical Trials Registry" as a clinical trial ID of UMIN000018641 on 8 August 2015. The study was performed in accordance with the relevant guidelines of the Declaration of Helsinki.

\section{Consent for publication}

Not applicable

\section{Competing interests}

The authors declare that they have no competing interests.

\section{Author details}

${ }^{1}$ Faculty of Clinical Engineering Technology, Fujita Health University School of Health Sciences, Dengakugakubo 1-98, Kutsukake-cho, Toyoake, Aichi 470-1192, Japan. ${ }^{2}$ Department of Nephrology, Kita-Saito Hospital, 9-choume 2-1, Miyashita-dori, Asahikawa, Hokkaido 070-0030, Japan. ${ }^{3}$ Department of Preventive Medicine, Nagoya University Graduate School of Medicine, Tsurumai-cho 65, Showa-ku, Nagoya, Aichi 466-8550, Japan. ${ }^{4}$ Division of Nephrology, Hypertension, and Endocrinology, Department of Internal Medicine, Nihon University School of Medicine, 30-1, Uemachi, Otaniguchi, Itabashi-ku, Tokyo 173-8610, Japan. ${ }^{5}$ Fourth Department of Internal Medicine, Tokyo Women's Medical University, Kawada-cho 8-1, Shinjyuku, Tokyo 162-8666, Japan
Received: 6 June 2020 Accepted: 29 October 2020

Published online: 03 December 2020

\section{References}

1. Nakai S, Masakane I, Akiba T, et al. Overview of regular dialysis treatment in Japan (as of 31 December 2005). Ther Apher Dial. 2007;11(6):411-41.

2. Pai $A B$, Smeeding JE, Brook RA. The role of sevelamer in achieving the kidney disease outcomes quality initiative (K/DOQI) guidelines for hyperphosphatemia. Curr Med Res Opin. 2004;20(7):991-9.

3. Egrie JC, Browne JK. Development and characterization of novel erythropoiesis stimulating protein (NESP). Nephrol Dial Transplant. 2001; 16(Suppl 3):3-13.

4. Nagano N. Pharmacological and clinical properties of calcimimetics: calcium receptor activators that afford an innovative approach to controlling hyperparathyroidism. Pharmacol Ther. 2006:109(3):339-65.

5. Drucker DJ, Nauck MA. The incretin system: glucagon-like peptide-1 receptor agonists and dipeptidyl peptidase-4 inhibitors in type 2 diabetes. Lancet. 2006;368(9548):1696-705.

6. Masakane I, Taniguchi M, Nakai S, et al. Annual Dialysis Data Report 2015, JSDT Renal Data Registry (JRDR). Renal Replace Ther. 2018;4:19. https://doi. org/10.1186/s41100-018-0149-8.

7. Shinzato T, Nakai S, Akiba T, et al. Survival in long-term haemodialysis patients: results from the annual survey of the Japanese Society for Dialysis Therapy. Nephrol Dial Transplant. 1997;12(5):884-8.

8. Abe M, Hamano T, Wada A, et al. Effect of dialyzer membrane materials on survival in chronic hemodialysis patients: results from the annual survey of the Japanese Nationwide Dialysis Registry. Plos One. 2017;12(9):e0184424.

9. Masakane I, Nakai S, Ogata S, et al. Annual dialysis data report 2014, JSDT Renal Data Registry (JRDR). Renal Replace Ther. 2017;3(18). https://doi.org/ 10.1186/s41100-017-0097-8.

10. Ministry of Health, Labor and Welfare Secretariat Statistics Information Department. Overview of 2015 simplified life table. (in Japanese) URL: http://www.mhlw.go.jp/toukei/saikin/hw/life/life15/ (Jan. 2020).

11. Ministry of Health, Labor and Welfare Secretariat Statistics Information Department. Life expectancy of Japanese. 2003 Simple Life Table. (in Japanese) URL: https://www.mhlw.go.jp/toukei/saikin/hw/life/life03/index. html (Jan. 2020).

12. United States Renal Data System. Chapter 5. Mortality. End-stage renal disease (ESRD) in the United States. In: 2018 USRDS annual data report: Epidemiology of kidney disease in the United States. Bethesda: National Institutes of Health, National Institute of Diabetes and Digestive and Kidney Diseases; 2018. p. 411-26.

13. ERA-EDTA Registry. Section B. Individual patient data reference tables. In: ERA-EDTA Registry Annual Report 2015. Amsterdam: Academic Medical Center, Department of Medical Informatics; 2017. p. 35-90.

14. United States Renal Data System. Chapter 5. Mortality. End-stage renal disease (ESRD) in the United States. In: 2017 USRDS annual data report: Epidemiology of kidney disease in the United States. Bethesda: National Institutes of Health, National Institute of Diabetes and Digestive and Kidney Diseases; 2017. p. 338-50.

15. Japanese Society for Dialysis Therapy. An overview of regular dialysis treatment in Japan (as of 31 December 2002). Ther Apher Dial. 2004;8(5): $358-82$.

16. Japanese Society for Dialysis Therapy. An overview of regular dialysis treatment in Japan as of 31 December 2003. Ther Apher Dial. 2005;9(6):43158.

17. U.S. Renal Data System. H. Mortality \& causes of death. In: USRDS 2005 Annual Data Report: Atlas of End-Stage Renal Disease in the United States. Bethesda: National Institutes of Health, National Institute of Diabetes and Digestive and Kidney Diseases; 2005. p. 497-574.

18. ERA-EDTA Registry: A5 Survival probability. ERA-EDTA Registry Annual Report 2004. Amsterdam: Academic Medical Center. Department of Medical Informatics; 2006. p. 46-78.

19. Robinson BM, Bieber B, Pisoni RL, Port FK. Dialysis Outcomes and Practice Patterns Study (DOPPS): its strengths, limitations, and role in informing practices and policies. Clin J Am Soc Nephrol. 2012;7(11):1897-905.

\section{Publisher's Note}

Springer Nature remains neutral with regard to jurisdictional claims in published maps and institutional affiliations. 